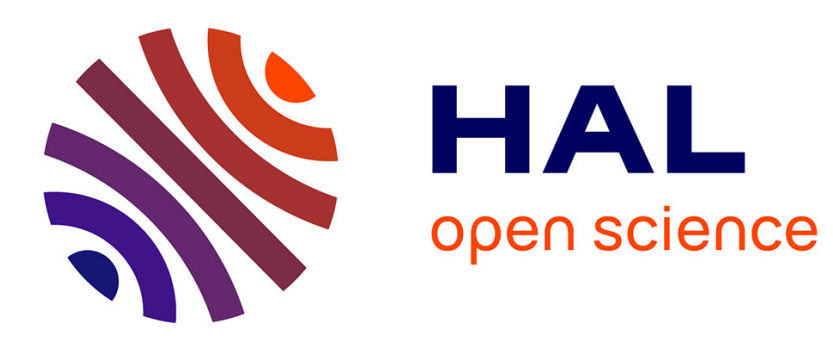

\title{
NUCLEATION OF Sb-MICROCRYSTALS IN AN INERT-GAS ATMOSPHERE
}

\author{
J. Mühlbach, E. Recknagel, K. Sattler
}

\section{To cite this version:}

J. Mühlbach, E. Recknagel, K. Sattler. NUCLEATION OF Sb-MICROCRYSTALS IN AN INERT-GAS ATMOSPHERE. Journal de Physique Colloques, 1980, 41 (C8), pp.C8-103-C8-106. 10.1051/jphyscol:1980827 . jpa-00220333

\section{HAL Id: jpa-00220333 https://hal.science/jpa-00220333}

Submitted on 1 Jan 1980

HAL is a multi-disciplinary open access archive for the deposit and dissemination of scientific research documents, whether they are published or not. The documents may come from teaching and research institutions in France or abroad, or from public or private research centers.
L'archive ouverte pluridisciplinaire HAL, est destinée au dépôt et à la diffusion de documents scientifiques de niveau recherche, publiés ou non, émanant des établissements d'enseignement et de recherche français ou étrangers, des laboratoires publics ou privés. 
NUCLEATION OF SB-MICROCRYSTALS IN AN INERT-GAS ATMOSPHERE

J. Mühlbach, E. Recknagel and K. Sattler

Eakultät für Physik, Universität Konstanz, D 7750 Konstanz, R.F.A.

Abstract.- The generation of antimony clusters in the size range from $\mathrm{Sb}_{1}$ to $\mathrm{Sb}_{500}$ is reported. The clusters are created by inert gas condensation and detected by a time-of-flight mass spectrometer. Condensation of clusters of known sizes onto a cold substrate is suggested as a technique which enables investigations of amorphous substances as a function of order.

To reveal the topology of amorphous solids a variety of model structures have been proposed: Random models, such as the continuous random network model (CRN) for covalent materials and the dense random packed model (DRP) for metals, compete with ordered models, such as the microcrystallite, amorphous cluster models, or the (random) dislocation/stacking models 1). However, by these theories the amorphous solid is described from extreme points of view, therefore it was suggested to compare structures of amorphous phases of the same substance produced by different methods ${ }^{2)}$, and to develop techniques, by which the extent of order can be determined ${ }^{1)}$. We consider condensation of clusters of known size on a cold substrate to be a possible preparation technioue to study properties of amorphous systems as a function of order. In the case of antimony, thin amorphous films (thickness $\mathrm{d} \approx 70 \stackrel{\circ}{\AA}$ ) deposited by evaporation from a PtSb source differ from films produced from elementary antimony in electrical resistance, light transmission, reaction with oxygen, and par- ticle size ${ }^{3)}$. The differences are attributed to antimony evaporating from $\mathrm{PtSb}$ predominantly as $\mathrm{Sb}$, atoms, as distinct from $\mathrm{Sb}_{4}$ clusters known to evaporate from elementary antimony. Sputtered films (d $\approx 1000 \AA$ ) exhibit an electrical resistance which is about one order of magnitude higher compared to the resistance of films evaporated from $\mathrm{Sb}$ or PtSb ${ }^{4)}$. A systematic investigation of amorphous substances composed of clusters as a function of cluster size was hindered so far by the lack of a suitable preparation technique for metallic microclusters (2-500 atoms). Sputtering or adiabatic expansion of metal vapour yield relative cluster intensities which decrease orders of magnitude with increasing cluster size. We present for the first time antinony clusters in the whole size range from $\mathrm{Sb}_{1}$ to $\mathrm{Sb}_{500}$, which are generated by inert gas condensation. The cluster intensities are monitored by a time-of-flight (TOF) mass spectrometer which is especially designed for the detection of metal clusters ${ }^{5)}$. The unexpectedly weak decrease of the relative cluster intensities yields a size 
distribution unavailable with other preparation techniques. The surprisingly high total intensity of the neutral cluster beam should even enable the preparation of probes composed of clusters of one size.

The schematic drawing of the cluster source is given in fig.1. The antimony particles emerging from the oven are cooled by collisions with He gas atoms in the condensation chamber. This leads to supersaturation and growth of clusters. The clusters pass the differential pumping section and enter the ionisation region of the mass spectrometer by the orifice 0 . They are ionized by pulsed electrons, the ionized clusters are accelerated to $2 \mathrm{keV}$ and after passing a $2 \mathrm{~m}$ long drift section they are detected by single ion analysis. As all the clusters have the same kinetic energy, their masses can be determined by their times of flight. A time-to-digital converter generates a complete TOF mass spectrum in a multichannel analyser. BY a synchronized electron deflection system single masses can be separated out of the whole cluster spectrum 5 ). Above the ionization region of the mass spectrometer a film thickness monitor is installed to measure the total intensity of the neutral cluster beam. If the oven is heated without $\mathrm{He}$ in the condensation chamber, predominantly $\mathrm{Sb}_{4}$ is found in the mass spectrum (intensity ratio $\mathrm{Sb}_{4}: \mathrm{Sb}_{3}: \mathrm{Sb}_{2}: \mathrm{Sb}_{1}=$ $77: 6: 8: 9, T=800 \mathrm{~K}$ ). Clusters of higher masses are not observed. When He is let into the $\mathrm{LN}_{2}$-cooled condensation chamber,

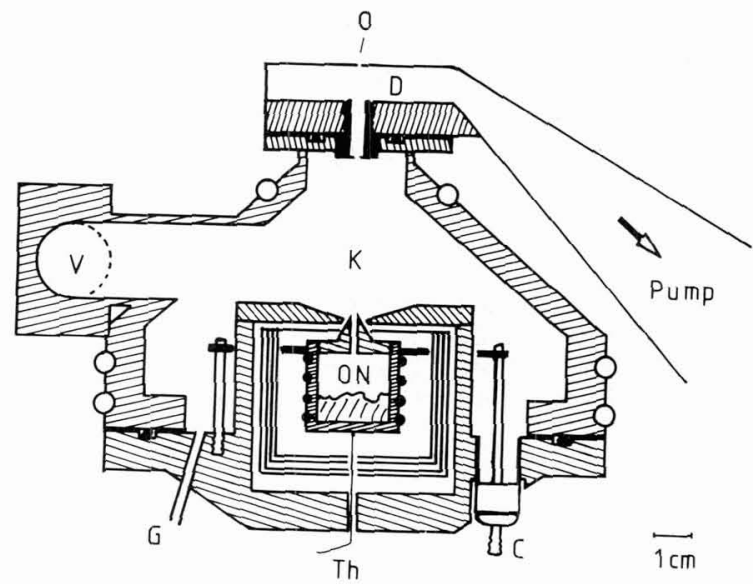

Fig.1: Clustersource for metal microclusters.

C currentfeedthrough, G gasinlet, V valve, $K$ condensation chamber, $D$ section of differential pumping, o orifice to the mass spectrometer, ON oven, Th thermocouple.

at $p=15$ Torr resolved cluster peaks up to $\mathrm{Sb}_{100}(12200 \mathrm{amu})$ are found in the TOFspectrum (fig.2), unresolved clusters are detected up to $\mathrm{Sb}_{500}$. The size distribution exhibits an unexpectedly weak decrease of the relative cluster intensities: Related to $\mathrm{Sb}_{4}$, we find $\mathrm{I}\left(\mathrm{Sb}_{16}\right)=84 \%$, $I\left(\mathrm{Sb}_{32}\right)=32 \%, I\left(\mathrm{Sb}_{64}\right)=9 \%$. Below $\mathrm{Sb}_{16}$, every cluster mass is found in the spectrum, above $\mathrm{Sb}_{16}$ a sequence $\mathrm{Sb}_{4 \mathrm{n}}$ dominates, which is attributed to clustering of $\mathrm{Sb}_{4}$-tetramers, which evaporate predominantly from an antimony surface."

\footnotetext{
(*) We cannot exclude that fragmentation occurs in the ionization process. Such influences on the cluster spectra will be investigated in future by variation of the ionization energy.
} 


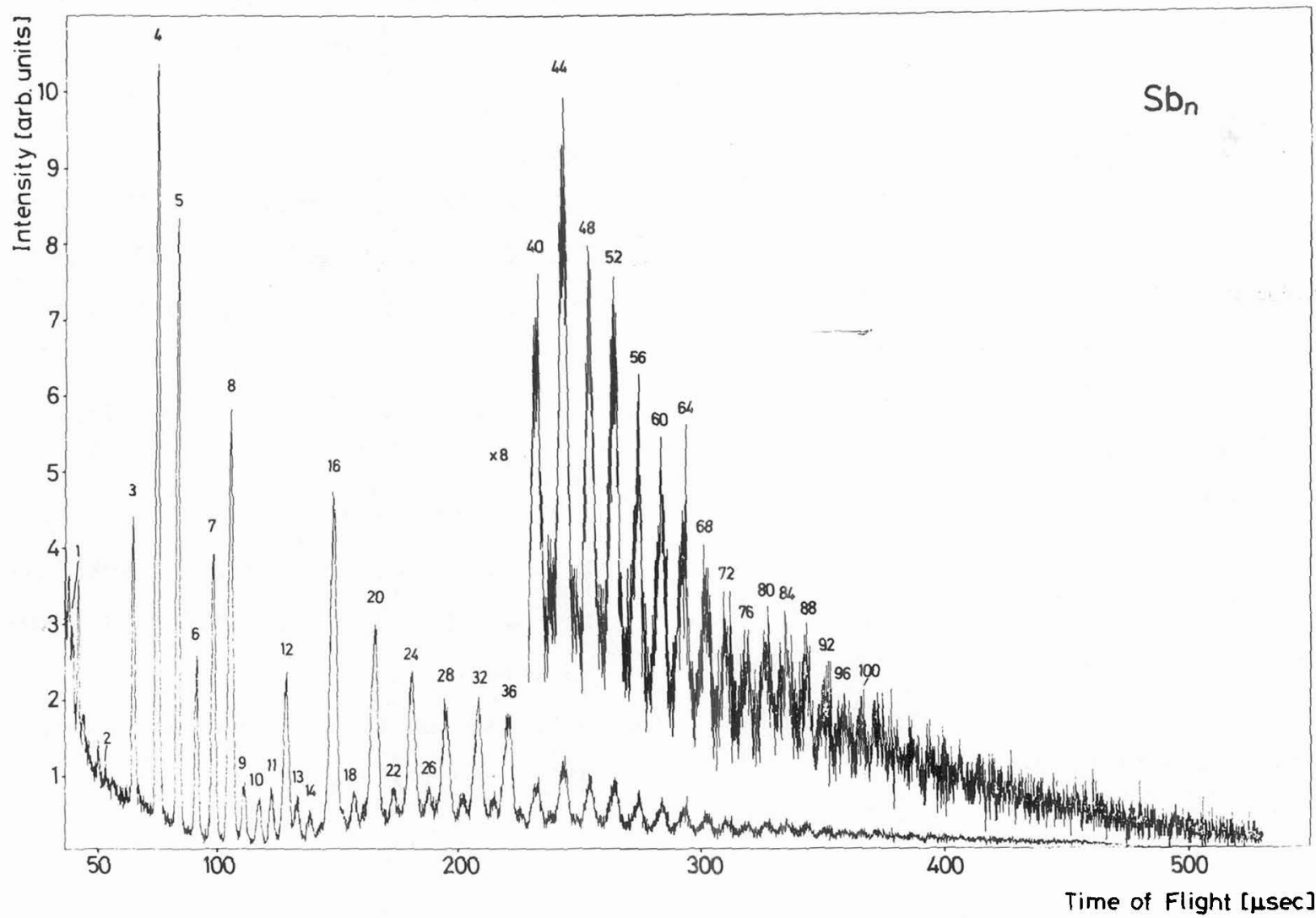

Fig. 2: TOF-mass spectrum of $\mathrm{Sb}$ clusters generated by inert gas condensation in He. $\mathrm{T}_{\text {oven }}=870 \mathrm{~K}, \mathrm{~T}_{\text {cond. }}$ chamber $=110 \mathrm{~K}$,

With $p_{\mathrm{He}}=15$ Torr, at the film thickness monitor an evaporation rate of about $10 \AA /$ sec is registered, which is about two to three orders of magnitude higher compared to the intensity obtained without He in the condensation chamber. Presumably a He flow characteristics establishes which centers the cluster beam. If the temperature of the condensation chamber is increased from $110 \mathrm{~K}$ to $130 \mathrm{~K}$, the flow characteristics is destroyed and the intensity at the film thickness monitor gets zero.
$\mathrm{p}_{\mathrm{He}}=15$ Torr. The unresolved part of the spectrum ranges uo to $820 \mu \mathrm{sec}$ (not shown), corresponding to a clustersize of $\mathrm{Sb}_{500}$.

A condensation rate of $10 \AA / \mathrm{sec}$ is sufficient even to produce thick films. Therefore, a preparation of amorphous substrates by condensation of $\mathrm{Sb}$-clusters having the size distribution shown in fig. 2 is possible. A variation of the size distribution can be performed by changing the parameters which govern the condensation process, and be nonitored by the TOF-spectrometer. Perhaps by this technique a solid can be obtained whose structure is the analogon of the model structure which is employed in the theory 
of paracrystalline microdomaines in liquids ${ }^{6)}$.

For a systematic investigation of the amorphous state as a function of order it would be even more interesting to generate amorphous probes by condensation of clusters of one unique mass. As mentioned above, clusters of unique mass can be separated out of the whole spectrum by TOFtechnique. The intensity of a typical cluster, e.g. $\mathrm{Sb}_{24}$, is $10 / \mathrm{sec}$. An estimation of possible improvements to obtain higher intensity makes us believe that the realisation of this preparation technique should be practicable.
This work was partly supported by the Deutsche Forschungsgemeinschaft.

\section{References}

1) P.H. Gaskel1, J.Phys.C12, 4337 (1979).

2) J.I. Finney, The Structure of NonCrystalline Materials, p.35 (Taylor and Francis, London 1977).

3) A.H. Sommer, J.Appl.Phys. 37, 2789 (1966).

4) J.J. Hauser, Phys.Rev. B9, 2623 (1974).

5) K. Sattler, J. Mühlbach, E. Recknagel and A. Reyes Flotte, J.Phys.E13 (19,80) in print.

6) M.S. Zei and R. Hosemann, Phys.Rev. $\underline{B 18}, 6560(1978)$. 